\title{
ELECTROCARDIOGRAPHIC PROFILE OF DILATED CARDIOMYOPATHY IN PATIENTS ATTENDING A TERTIARY CARE HOSPITAL OF WESTERN NEPAL
}

\author{
Ram Chandra Kafle ${ }^{1}$, Navaraj Paudel ${ }^{1}$, Dibya Sharma², Vijaya Madhav Alurkar
}

\begin{abstract}
\section{INTRODUCTION}

Cardiomyopathy is a disease of the heart muscle that leads to deterioration of myocardial functioning. It has different morphological variation with dilated cardiomyopathy being the most common form comprising over $90 \%$ of all cases. Heart failure (HF) is the most common clinical presentation of dilated cardiomyopathy. Various electrocardiographic changes are common in these patients. The most common cause of sudden death in these patients is arrhythmia. This study aimed at characterizing different electrocardiographic changes in patients of dilated cardiomyopathy admitted for heart failure.
\end{abstract}

\section{MATERIAL AND METHODS}

A retrospective analysis of records of admitted patients from $1^{\text {st }}$ January 2015 to $30^{\text {th }}$ April 2018 was conducted. Study was conducted after obtaining ethical clearance from institutional review board. Data was collected in a preformed proforma and analyzed using SPSS 20.0 version.

\section{RESULTS}

Consecutive 400 cases of dilated cardiomyopathy with systolic dysfunction ( $\mathrm{LVEF}<40 \%$ ) were taken for the study. Two hundred and fifty two (63\%) were male. The mean age of patients was $59.33( \pm 15.76)$ years. The most common risk factors in our patients were smoking (66\%) followed by systemic hypertension (49\%), IHD (32\%), and diabetes mellitus (33\%) respectively. Out of 400 patients, abnormal ECG were found in $82.5 \%$. The most common abnormality was LVH (30.7\%) followed by $\operatorname{LBBB}(22.5 \%)$ and $\mathrm{AF}(20.5 \%)$.

\section{CONCLUSION}

The percentage of abnormal electrocardiographic findings was high in our study. All patients of dilated cardiomyopathy should undergo electrocardiography screening for risk stratification and to prevent serious consequences with early necessary intervention.

KEYWORDS Arrhythmia, dilated cardiomyopathy, ECG changes, heart failure

1. Lecturer, Department of Cardiology, Manipal Teaching Hospital, Phulbari-11, Pokhara, Nepal

2. Assistant Professor, Nursing Program, Manipal College of Medical Sciences, Phulbari -11, Pokhara, Nepal

3. Professor, Department of Cardiology, Manipal Teaching Hospital, Phulbari -11, Pokhara, Nepal

For Correspondence

Ram Chandra Kafle

Lecturer

Department of Internal Medicine

Manipal College of Medical Sciences

Pulbari-11, Pokhara

Email: drkafle30@gmail.com. 


\section{INTRODUCTION}

Cardiomyopathy is a disease of the heart muscle that leads to deterioration of myocardial functioning ${ }^{1}$. According to the World Health Organization (WHO) and American Heart Association (AHA), cardiomyopathy is categorized as dilated cardio-myopathy (DCM), hypertrophic cardiomyopathy (HCM), restrictive cardiomyopathy (RCM), obliterative cardiomyopathy (OCM) and arrhythmogenic right ventricular cardiomyopathy (ARVC) ${ }^{2,3}$ DCM is the most common form comprising over $90 \%$ of all cases causing sudden cardiac death ${ }^{4}$ DCM is considered to be an important cause of heart failure and accounts for up to $25 \%$ of all cases of $\mathrm{CHF}^{5}$.

Heart failure (HF) is an increasingly costly and deadly manifestation of a series of cardiac diseases and constitutes a major public health problem worldwide ${ }^{6,7}$.

Despite current state-of-the-art treatment of HF, mortality rate remains high, and around $5060 \%$ of HF patients will die within five years of diagnosis ${ }^{6}$. HF is also associated with increased morbidity as it is characterized by frequent hospital admissions and prolonged hospital stay ${ }^{8}$ Chronic heart failure is a complex clinical syndrome that can result from a number of functional or structural cardiac disorders, impairing the ventricle's ability to fill with or eject blood ${ }^{9}$. Electrical conduction abnormalities are common in heart failure and lead to cardiac arrhythmias and sudden cardiac death ${ }^{10}$.

Patients with DCM present a wide variety of electro cardiographic manifestations including bundle-branch block or conduction disturbances, low or high QRS amplitude, abnormal Q-waves, and ST-T wave changes. None of these are specific to, nor diagnostic for DCM. It may be that the variety of electrocardiographic abnormalities reflects the severity of myocardial damage and could be a predictor of the prognosis of patients with DCM.

Currently, there is paucity of data on dilated cardiomyopathy in Nepal. With rising prevalence of chronic heart failure in the country and the availability of echocardiogram (Echo), the incidence of dilated cardiomyopathy is also showing a rising trend. This study aimed at characterizing different electrocardiographic changes in patients of dilated cardiomyopathy admitted for heart failure.

\section{MATERIAL AND METHODS}

A retrospective study design was used to conduct the present study. A retrospective analysis of records among patients admitted with diagnosis of dilated cardiomyopathy with systolic dysfunction ( $\mathrm{LVEF}<40 \%$ ). A sample size of 400 was taken from the hospital record from $1^{\text {st }}$ January 2015 to $30^{\text {th }}$ April 2018. The data was collected as per the attached proforma. Collected data were entered into a master chart prepared in Microsoft Excel 2007 which is checked, verified and converted into SPSS 20.0 version for statistical analysis. Descriptive statistics like mean, percentage, frequency, standard deviation was used to describe ECG changes in patients of systolic heart disease.

Patients admitted for first time during study period with diagnosis of dilated cardiomyopathy with systolic heart failure (LVEF $<40 \%$ ) were enrolled. All eligible subjects agreed to participate in the study. Patient who are not willing to participate were excluded from the study.

Study was conducted after obtaining ethical clearance from institutional review board.

\section{Electrocardiography}

Standard 12-lead ECGs were recorded at $25 \mathrm{~mm} / \mathrm{s}$ and 10 $\mathrm{mm} / \mathrm{mv}$. For each lead, $\mathrm{R}$ wave and $\mathrm{S}$ wave voltages were measured from the PR segment to the top of the R wave and the bottom of the S wave, respectively. Sokolow's criterion (S wave in lead V] [SV1] + R wave in lead V5 or V6 [RV5 or RV6] > $35 \mathrm{~mm}$ 7) for LV hypertrophy ${ }^{11}$.

\section{Echocardiography}

According to the recommendations of the American Society of Echocardiography, LV internal dimension (LVID), intraventricular septum (IVS), and posterior wall thickness (PWT) were measured peak of the R wave on the ECG. LV internal dimension was used as an index of LV dilatation, and wall thickness of IVS and PWT, were used as indices of LV hypertrophy ${ }^{12}$.

\section{RESULTS}

A retrospective analysis of records among patients admitted with dilated cardiomyopathy and systolic dysfunction $\left(\mathrm{LVEF}<40 \%\right.$ ) from $1^{\text {st }}$ January 2015 to $30^{\text {th }}$ April 2018 with a sample size of 400 was taken.

Table 1. Socio-demographic characteristics of the patients $(n=400)$

\begin{tabular}{|l|l|l|}
\hline Age group (yrs) & Frequency (f) & Percentage (\%) \\
\hline$\leq 30$ & 32 & 8 \\
$31-60$ & 160 & 38 \\
$>60$ & 208 & 54 \\
\hline Mean \pm SD & $57.36 \pm 13.77$ & \\
\hline Gender & & \\
Male & 252 & 61 \\
Female & 148 & 39 \\
\hline
\end{tabular}

More than half $(52 \%)$ of the patients were in age group $>60$ years with mean age of patient was $57.36( \pm 13.77)$ years. Out 
of 400 patients enrolled 244 (61\%) were males and $156(39 \%)$ were females (Table 1).

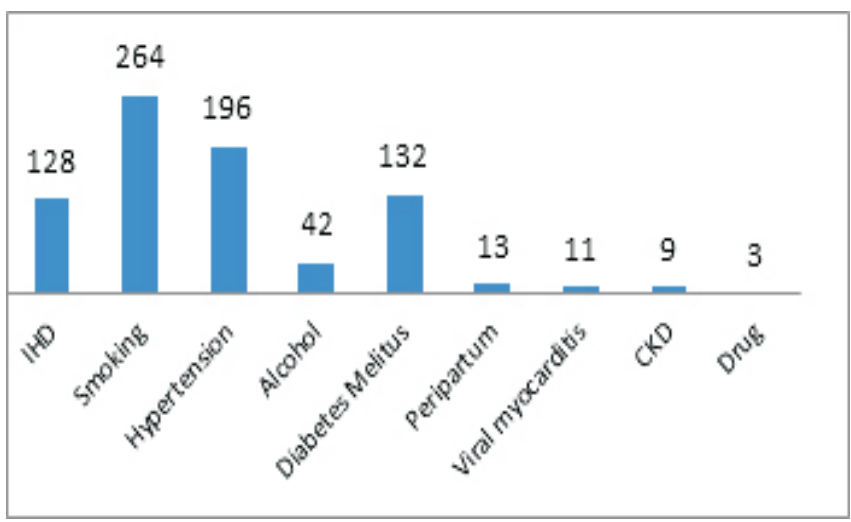

Figure 1. Risk factors associated for dilated cardiomyopathy

The most common risk factor in patients was smoking $(66 \%)$ followed by systemic hypertension (49\%), IHD (32\%), and diabetes mellitus (33\%) (Figure 1).

Table 2. ECG changes in patients with $\operatorname{DCM}(n=400)$

\begin{tabular}{|c|c|c|}
\hline Characteristics & Frequency (f) & Percentage (\%) \\
\hline Abnormal ECG & 349 & 87.25 \\
\hline LVH & 123 & 30.75 \\
\hline Sinus Tachycardia & 79 & 19.1 \\
\hline Left axis deviation & 53 & 13.25 \\
\hline Nonspecific ST/T changes & 76 & 19 \\
\hline Q Wave Anterior & 29 & 7.25 \\
\hline Inferior & 13 & 3.25 \\
\hline \multicolumn{3}{|l|}{ Arrhythmia in DCM patients } \\
\hline $\mathrm{AF}$ & 94 & 23.5 \\
\hline Atrial premature complex & 58 & 14.5 \\
\hline VPCs in isolation & 69 & 17.25 \\
\hline Ventricular bigeminy & 16 & 4 \\
\hline \multicolumn{3}{|l|}{24 hour holter recording } \\
\hline Supra ventricular tachycardia & 9 & 2.25 \\
\hline Non-sustained VT & 12 & 3 \\
\hline Sustained VT & 7 & 1.75 \\
\hline \multicolumn{3}{|c|}{ Conduction abnormality in DCM patients } \\
\hline LBBB & 102 & 25.5 \\
\hline RBBB & 34 & 8.5 \\
\hline Non-specific IVCD & 66 & 17.5 \\
\hline A-V block & & \\
\hline $3^{\text {rd }}$ & 2 & 0.5 \\
\hline $2^{\text {nd }}$ type I & 7 & 1.75 \\
\hline $2^{\text {nd }}$ type II & 3 & 0.75 \\
\hline $1^{\text {st }}$ & 23 & 5.75 \\
\hline
\end{tabular}

The study notified that $87.25 \%$ of patients had abnormal ECG. The most common abnormality was LVH (30.75\%) followed by $\operatorname{LBBB}(25.5 \%)$ and $\operatorname{AF}(23.5 \%)$ (Table 2$)$.
Table 3. Echocardiographic findings of the patients

$(n=400)$

\begin{tabular}{|c|c|c|}
\hline Characteristics & Frequency & Percentage (\%) \\
\hline $\begin{array}{l}\text { LA Size } \\
<4 \\
4-5.5 \\
>5.5 \\
\end{array}$ & $\begin{array}{l}135 \\
259 \\
6\end{array}$ & $\begin{array}{l}33.75 \\
64.75 \\
1.5\end{array}$ \\
\hline $\begin{array}{l}\text { LVEF (\%) } \\
20-25 \\
26-30 \\
31-35 \\
36-40\end{array}$ & $\begin{array}{l}27 \\
79 \\
134 \\
160\end{array}$ & $\begin{array}{l}6.75 \\
19.75 \\
33.5 \\
40\end{array}$ \\
\hline $\begin{array}{ll}\text { MR } & \\
& \text { Mild } \\
& \text { Moderate } \\
& \text { Severe } \\
\end{array}$ & $\begin{array}{l}338 \\
139 \\
168 \\
31\end{array}$ & $\begin{array}{l}84.5 \\
34.75 \\
42 \\
7.75 \\
\end{array}$ \\
\hline $\begin{array}{l}\text { TR } \\
\text { Mild } \\
\text { Moderate } \\
\text { Severe } \\
\end{array}$ & $\begin{array}{l}73 \\
124 \\
49\end{array}$ & $\begin{array}{l}18.25 \\
31 \\
12.25\end{array}$ \\
\hline $\begin{array}{l}\text { LVDD } \\
\text { Grade I } \\
\text { Grade II } \\
\text { Grade III }\end{array}$ & $\begin{array}{l}227 \\
151 \\
23\end{array}$ & $\begin{array}{l}56.75 \\
37.75 \\
5.75\end{array}$ \\
\hline $\begin{array}{l}\text { Pulmonary hypertension } \\
\text { Mild } \\
\text { Moderate } \\
\text { Severe }\end{array}$ & $\begin{array}{l}285 \\
232 \\
79 \\
17\end{array}$ & $\begin{array}{l}71.25 \\
58 \\
19.75 \\
4.25\end{array}$ \\
\hline $\begin{array}{l}\text { Regional wall hypokinesia } \\
\text { Mid and apical septal } \\
\text { Antero-lateral } \\
\text { Inferior } \\
\text { Anterior and inferior }\end{array}$ & $\begin{array}{l}90 \\
65 \\
11 \\
9 \\
5\end{array}$ & $\begin{array}{l}22.5 \\
16.25 \\
2.75 \\
2.25 \\
1.25\end{array}$ \\
\hline Global wall hypokinesia & 308 & 77 \\
\hline $\begin{array}{l}\text { Pericardial effusion } \\
\text { Small } \\
\text { Medium } \\
\text { Large }\end{array}$ & $\begin{array}{l}177 \\
136 \\
33 \\
8\end{array}$ & $\begin{array}{l}44.25 \\
34 \\
8.25 \\
2 \\
\end{array}$ \\
\hline Intracardiac Thrombus & 9 & 2.25 \\
\hline
\end{tabular}

Table 3 shows mitral regurgitation (84.5\%), LVDD grade II $(37.75 \%)$, tricuspid regurgitation $(61.5 \%)$ and Ejection fraction of 31 to $35 \%$ in $33.5 \%$.

Table 4. Echocardiographic findings of the patients

$(\mathrm{n}=400)$

\begin{tabular}{|l|c|c|c|c|}
\hline Characteristics & Minimum & Maximum & Mean & Std. deviation \\
\hline LA Size(mm) & 36 & 57.7 & 38.1 & 10.3 \\
LVEDd (mm) & 56.2 & 85.7 & 62.3 & 7.2 \\
LVESd (mm) & 38 & 69 & 50.5 & 6.7 \\
EPSS(mm) & 7.3 & 37.6 & 20.9 & 5.3 \\
FS (\%) & 9 & 21 & 16.74 & 2.3 \\
LVEF (\%) & 20 & 40 & 34.9 & 4.7 \\
TAPSE(mm) & 7 & 25 & 16.3 & 3.7 \\
\hline
\end{tabular}

Echocardiographic study showed mean LA 38.1( \pm 10.3$) \mathrm{mm}$, LVIDd $62.3( \pm 7.2) \mathrm{mm}$, LVIDs 51( \pm 6.7$)$, LVEF $34.9( \pm 4.7)$ $\%$, EPSS $21( \pm 5.1) \mathrm{mm}$, fractional shortening $(16.74 \pm 2.2) \%$, TAPSE16.3 ( \pm 3.7$) \mathrm{mm}$ (Table 4). 
Table 5. Etiology of dilated cardiomyopathy $(n=400)$

\begin{tabular}{|l|l|l|}
\hline Etiology & Frequency & Percentage (\%) \\
\hline Ischemic & 132 & 33 \\
Idiopathic & 128 & 32 \\
Alcohol induced & 42 & 10.5 \\
HTN & 196 & 49 \\
Peripartum cardiomyopathy & 13 & 3.25 \\
Viral Myocarditis & 11 & 2.75 \\
Valvular heart disease & 8 & 2 \\
CKD & 9 & 2.25 \\
Drug & 4 & 1 \\
\hline
\end{tabular}

The most common cause of dilated cardiomyopathy was ischemic heart disease (33\%) followed by idiopathic (32\%), Alcohol induced and systemic hypertension in $10.5 \%$ each (Table 5).

\section{DISCUSSION}

The current study observed the various electrocardiographic and echocardiographic changes among the patients with dilated cardiomyopathy in 400 patients. The present study showed the most common risk factors in our patients were smoking $(66 \%)$ followed by systemic hypertension (49\%), IHD (32\%), and diabetes mellitus (33\%) analogous with study by Anh L. Bui ${ }^{13}$ The ECG finding in the patients with dilated cardiomyopathy revealed the most common abnormality was LVH (30.75\%) followed by LBBB (25.5\%), AF (23.5\%) and RBBB (8.5\%). Similar results were obtained in a study from eastern India showing $21.4 \% \mathrm{LBBB}$ and $11.4 \% \mathrm{RBBB}^{14}$. Sonowal et al showed analogous result with LVH (41.94\%), atrial fibrillation $(22.58 \%)$ and bundle branch block (29\%) ${ }^{15}$. Another comparable findings were noted by Patil et al. with LBBB (24\%), RBBB (4.6\%) and AF (9.23\%) ${ }^{16}$ whereas a study conducted in Vadodara, India revealed sinus tachycardia $(53 \%)$ as a predominant finding followed by LVH $(13.33 \%)$ and RBBB (13.16\%) ${ }^{17}$ respectively. A study in Kenya showed dissimilar result showing LVH (8.8\%), LBBB (30.6\%), AF $(31.5 \%){ }^{18}$

Conduction abnormalities were found in $60.25 \%$ of cases which included $1 \mathrm{st}(5.75 \%), 2^{\text {nd }}(2.5 \%)$ and $3^{\text {rd }}(0.5 \%)$ degree A-V block, LBBB, LAFB, non- specific IVCD and RBBB which is lower than the study by Roberts $\mathrm{WC}^{19}$ and Wilensky $\mathrm{RL}^{20}$ where conduction abnormalities occurred in over $80 \%$ of cases. Patil et al noted lower rate of conduction abnormalities $(47.65 \%)$ where $1^{\text {st }}, 2^{\text {nd }}$ and $3^{\text {rd }}$ degree heart block were found in $3.07 \%, 1.53 \%$ and $1.53 \%$ respectively $^{16}$. The present study showed non-sustained ventricular tachycardia (VT) in $12(3 \%)$ cases and sustained VT in seven $(1.75 \%)$ cases in 24 hour-holter recording. These findings are strong predictors of future cardiac events as shown in the study by Zareba $\mathrm{W}^{21}$ and Ponikowski $\mathrm{P}^{22}$.
Abnormal Q waves (10.5\%) and ST-T segment abnormalities $(19 \%)$, which are more commonly observed in CAD, are also seen in patients with DCM ${ }^{23,19}$ Berbard G confirmed that patient with dilated cardiomyopathy had pathological Q wave (5.6\%) and ST segment abnormalities $(34.3 \%){ }^{17}$. Patil et al. revealed the ST depression (18.46\%) and QS pattern (16.92\%) ${ }^{16}$ Johnson et al. reported that abnormal Q waves were seen in $70 \%$ of patients with CAD and LV dysfunction and in I0\% of patients with DCM, and that ST-T segment abnormalities were present in both groups of patients ${ }^{23}$

Echocardiographic study showed mean LA $38.1( \pm 10.3) \mathrm{mm}$, LVIDd $62.3( \pm 7.2) \mathrm{mm}$, LVIDs $50.5( \pm 6.7)$, LVEF $34.9( \pm$ $4.7) \%$, EPSS $20.9( \pm 5.1) \mathrm{mm}$, fractional shortening $(16.74 \pm$ $2.3) \%$, TAPSE16.3 $( \pm 3.7) \mathrm{mm}$ which is similar to study by Ali $\mathrm{M}$ et al ${ }^{24}$ and Echeverria $\mathrm{HH}$ et al ${ }^{25}$. The mean LV ejection fraction in a study conducted in Bareilly was $30.87 \%$ which is in line with the present study (34\%) ${ }^{26}$. Another comparable findings were acquired by Banerjee SK et al where LVEF was $28( \pm 8) \%{ }^{27}$. Echocardiography findings of the study showed that mitral regurgitation (84.5\%), LVDD grade II $(37.75 \%)$, tricuspid regurgitation (61.5\%), ejection fraction of 31 to $35 \%$ is $33.5 \%$ which is similar to the study conducted by Saxena et al. with mitral regurgitation (73.3\%), LVDD grade II (33.3\%) ejection fraction of 31 to $39 \%$ in $35 \%{ }^{26}$. Another identical finding was accomplished by Rana et al. with ejection fraction of 31 to $35 \%$ in $26 \%$, tricuspid regurgitation $(63.3 \%)$, mitral regurgitation $(48.66 \%){ }^{17}$. The most common cause of dilated cardiomyopathy was ischemic heart disease (33\%). Other common causes were idiopathic (32\%), alcohol induced and systemic hypertension in $10.5 \%$ each, peripartum cardiomyopathy and viral myocarditis in $4.5 \%$ each, valvular and CKD in $2 \%$ each, drug (1\%). Kasper EK et al found that $46.6 \%$ cases idiopathic, other common specific cardiomyopathies included ischemic 11\%, HIV related $4.9 \%$, peripartum $4.9 \%$ alcoholic $3.4 \%$, hypertensive $2.1 \%$ and valvular $1.5 \%{ }^{28}$. A study conducted in north east India documented that main cause of cardiomyopathy is idiopathic (41.93\%), alcohol (22.58\%) and peripartum $(22.58 \%)^{15}$

The current study has few limitations. The assessment of the ECGs with inter-individual variability during the placement of chest leads may have occurred. Another limitation lies in the echocardiographic measurements where technical errors may have occurred in the measurements of wall thickness and LV internal dimension. The retrospective nature of this study is also a limitation.

\section{CONCLUSION:}

The percentage of abnormal electrocardiographic findings was high in our study with some changes that have serious consequences. All patients of dilated cardiomyopathy should 
undergo electrocardiography screening for risk stratification and to prevent serious consequences with early necessary intervention.

\section{ACKNOWLEDGEMENT}

We are thankful to all the patients and their relatives for cooperating us.

\section{CONFLICT OF INTEREST}

The authors declare that there is no conflict of interest regarding the publication of this article.

\section{REFERENCES}

1. Zipes D, Libby P, Bonow R, Braunwald E. A Braunwald's heart disease -Textbook of Cardiovascular Medicine, Di-lated cardiomyopathy, 9th Ed. Philadelphia. Elsivier Saunders; 2012.p1563-69.

2. Richardson P, McKenna W, Bristow M, Maisch B, Maut-ner B, O.Connell J, et al. Report of the 1995 WHO / Inter-national Society and Federation of Cardiology (ISFC) Task Force on the Definition and Classification of cardi-omyopathies. Circulation 1995;93:841-2.

3. Maron BJ, Towbin JA, Thiene G, Antzelevitch C, Corrado D, Arnett D, et al. Contemporary definitions and classifi-cation of the cardiomyopathies. Circulation 2006;113:1807-16.

4. Cohn JN, Bristow MR, Chien KR. Report of the national heart, lung, and blood institute special emphasis panel on heart failure research. Circulation 1997;95:766-70.

5. Anderson KM, Kannel WB. Prevalence of congestive heart failure in Framingham Heart study subjects. Circu-lation 1994;13:S107-S112.

6. Cygankiewicz I, Zaręba W, De Luna AB. Prognostic value of Holter monitoring in congestive heart failure. Cardiol J. 2008;15(4):313323.

7. Bloomfield GS, Barasa FA, Doll JA, Velazquez EJ. Heart failure in Sub-Saharan Africa. Curr Cardiol Rev. 2013;9 (2):157173

8. Wright SP, Verouhis D, Gamble G, Swedberg K, Sharpe N, Doughty RN. Factors influencing the length of hospital stay of patients with heart failure. Eur J Heart Fail. 2003;5(2):2019.

9. Figueroa MS, Peters JI. Congestive heart failure: diagnosis, pathophysiology, therapy, and implications for respiratory care. Respir Care 2006;51:40312.

10. Chronic Heart Failure: The Management of Adults with Chronic Heart Failure in Primary and Secondary Care (Partial Update). National Institute for Health and Clinical Excellence, 2010. Available at: http://www. nice.org.uk/guidance/cg108 /resources / guidance-chronic-heart-failure-pdf)
11. Spodick DH, Koito H. Differential sensitivity of the RV6: RV5 voltage ratio by pathogenesis of left ventricular hypertrophy and diagnostic cutpoint. Am J Cardiol 1989;64(12):817-9.

12. Devereux RB, Reichek N: Echocardiographic determination of left ventricular mass in man: anatomic vali- dation of the method. Circulation. 1977;55:613-8.

13. Bui AL, Horwich TB, Fonarow GC. Epidemiology and risk profile of heart failure. Nat Rev Cardiol. 2011 Jan; 8(1): 3041.

14. Paul R, Nandi S, Sihna PK. Epidemiological study of dilated cardiomyopathy from Eastern India with special reference to left atrial size. Int J Med Res Health Sci. 2014;3(3):63944.

15. Sonowal N, Rao VD. Clinical Profile of Patients with Dilated Cardiomyopathy in a Tertiary Care Center in North East India. J of Evolution of Med and Dent Sci 2014; 3(30): 8378-86, DOI: $10.14260 /$ jemds/2014/3056.

16. Patil VC, Desai N, Galande C. Clinical and echocardiogram profile of Cardiomyopathy at tertiary care centre. Journal of Cardiovascular Disease Research 2014; 5(1):1-10.

17. Rana HM, Chavda P, Rathod CC, Mavani M. Electro cardiographic And Echocardiographic Profile Of Dilated Cardiomyopathy Patients Attending Tertiary Care Hospital In Vadodara. National Journal of Community Medicine 2015; 6(4):571-4.

18. Bernard G. Prevalence of electrocardiographic abnormalities in patients with dilated cardiomyopathy at kenyatta national hospital [Dissertation], University of Nairobi; 2013.

19. Roberts WC, Siegel RJ, McManus BM. Idiopathic dilated cardiomyopathy: analysis of 152 necropsy patients Am J Cardiol. 1987;60(16):1340-55

20. Wilensky RL, Yudelman P, Cohen AI, Fletcher RD, Atkinson J, Virmani R, et al. Serial electrocardiographic changes in idiopathic dilated cardiomyopathy confirmed at necropsy. Am J Cardiol. 1988;62(4):276-83

21. Zareba W, Moss AJ. Noninvasive risk stratification in postinfarction patients with severe left ventricular dysfunction and methodology of the MADIT II noninvasive electro cardiology substudy. J Electrocardiol. 2003;36 Suppl 1:101-8

22. Ponikowski P, Anker SD, Amadi A, Chua TP, Cerquetani E, Ondusova D et al. Heart rhythms, ventricular arrhythmias, and death in chronic heart failure. J Card Fail. 1996 Sep;2(3):17783.

23. Johnson RA, Palados I: Dilated cardiomyopathies of the adult (first of two parts). N Engl J Med 21:1051, I982.

24. Ali M, Faruqui AMA. Dilated cardiomyopathy experience in Pakistan. Pakistan Heart Journal. 1984;17(1):27-34.

25. Echeverria HH, Bilsker MS, Myerburg RJ, Kessler KM. Congestive heart failure: echocardiographic insights. Am J Med. 1983 Nov;75 (5):750-5. 
26. Banerjee SK, Rahman F, Salman M, Siddique MA, Zaman SMM, Anam K, et al. Idiopathic dilated cardiomyopathy: clinical profile of 100 patients. University Heart Journal. 2010; 6(1):9-12.

27. Saxena NK, Mehra D. Study of Dilated Cardiomyopathy in Correlation with Electrocardio-graphy and Echocardiography in Patients less than 40 Years Age, in Bareilly. International Journal of Contemporary Medical Research 2018;5(3):C31-34.
28. Kasper EK, Agema WR, Hutchins GM, Deckers JW, Hare JM, Baughman KL. The causes of dilated cardiomyopathy: a clinicopathologic review of 673 Consecutive patients. J Am Coll Cardiol. 1994;23(3):586-90. 